\title{
Female Hematozoan Infection Reduces Hatching Success but not Fledging Success in Pied Flycatchers Ficedula hypoleuca
}

\author{
Juan J. Sanz, ${ }^{1}$ Elena Arriero, Juan Moreno, and Santiago Merino \\ Departamento de Ecología Evolutiva, Museo Nacional de Ciencias Naturales (CSIC), José Gutiérrez Abascal 2, \\ E-28006 Madrid, Spain
}

\begin{abstract}
We report association between female blood parasite prevalence (percentage of infected birds) just after egg laying and reproductive success in two successive breeding seasons, in a breeding population of Pied Flycatcher Ficedula hypoleuca in central Spain. Females infected with Trypanosoma spp. had a higher probability of deserting their clutches during the incubation period than noninfected females. Females infected with Haemoproteus balmorali hatched proportionally fewer eggs than noninfected females. Female infected with $H$. balmorali during the incubation period may have a decreased ability to thermoregulate which may affect their incubation capacity. Fledging success, breeding success, fledgling mass, and tarsus length were not associated with infection of the mother by blood par-
\end{abstract}

\footnotetext{
${ }^{1}$ E-mail: sanz@mncn.csic.es
}

asites during the incubation period, suggesting that females and their mates may compensate during the nestling period for the negative effect of blood parasites during the incubation period.

Most parasites exert an intense selective pressure on their hosts by reducing their condition, survival prospects, mating, or reproductive performances (Loye and Zuk 1991, Møller 1997). That detrimental effect may vary in relation to parasite virulence. In order to understand evolutionary interactions occurring between parasites and their hosts, it is necessary to know the extent to which parasites have a detrimental effect on their hosts' reproduction and survival in wild populations. Reproductive success has been the target of many field studies of birds, because it is expected to relate closely to fitness (Stearns 1992). Blood parasites have been shown to negatively affect reproductive success of their hosts 
because they compete with the host for resources (e.g. review in Møller 1997). If blood parasites have a detrimental effect on their hosts, heavy parasite infections will correlate with low host reproductive success.

Most studies in wild populations have shown a negative effect of parasites on some measure of host reproduction (e.g. clutch size, fledging success; reviewed by Møller et al. 1990, Møller 1997). In particular, many studies have focussed on nestling survival. A problem of those correlative studies is that most birds were sampled at the end of the nestling period, after the main reproductive investment was performed by parents. In birds, high reproductive effort is positively correlated with blood parasite load both for natural clutch sizes (Korpimäki et al. 1993, Allander and Bennett 1995, Dufva 1996, Oppliger et al. 1997, Ilmonen et al. 1999) and for experimentally manipulated clutch sizes (Norris et al. 1994, Richner et al. 1995, Ots and Hõrak 1996, Allander 1997, Siikamäki et al. 1997, Wiehn and Korpimäki 1998, Fargallo and Merino 1999, Wiehn et al. 1999; but see Merino et al. 1996). If host reproductive effort increases susceptibility to blood parasite infection or the likelihood that latent, chronic infections may relapse, parasitism may be a consequence of reproductive effort, not its cause (Oppliger et al. 1997). Therefore, studies looking for effects of blood parasites on reproductive success in free living individuals should sample birds before their main reproductive investment is performed. Moreover, because reproduction and immunity are likely to compete for resources (Gustafsson et al. 1994, Sheldon and Verhulst 1996, Lochmiller and Deerenberg 2000, Norris and Evans 2000) and the total amount of energy a bird is able to put into both may depend on food availability (Appleby et al. 1999), studies looking for effects of blood parasites on reproductive success should sample birds under different ecological conditions.

We examined association between blood parasites (Haemoproteus balmorali, Trypanosoma spp.) and reproductive success of female Pied Flycatchers (Ficedula hypoleuca) breeding in central Spain. Blood parasites of females were sampled just after egg laying in two successive breeding seasons. We tested the hypothesis that blood parasites may negatively affect reproductive success of females by examining observed relationship between maternal blood parasite infection and hatching, fledging, and breeding success of Pied Flycatchers.

Methods.-The Pied Flycatcher is a small (12-13 g), migratory, sexually dichromatic, and hole-nesting passerine of European woodlands (Lundberg and Alatalo 1992). Egg laying in our study population typically begins in late May, and clutch size ranges from 2 to 8 eggs with a mode of 6 (Sanz 1997). The female incubates alone and during that period receives part of her food from her mate. Both sexes feed the young, which fledge within 15-18 days of hatching (Lundberg and Alatalo 1992).

The study was conducted during the springs of 1998 and 1999 in a deciduous forest of Pyrennean oak (Quercus pyrenaica) at 1,200 $\mathrm{m}$ above sea level in the vicinity of La Granja, central Spain $\left(40^{\circ} 54^{\prime} \mathrm{N}\right.$, $\left.04^{\circ} 01^{\prime} \mathrm{W}\right)$. Frequent checks of nest-boxes provided data on dates of clutch initiation and clutch size for all breeding pairs. On the day after clutch completion, females were captured and banded with numbered rings. Length of incubation was defined as number of days between completion of clutch and first signs of hatching. Nestlings were measured and ringed on day 13 after hatching (hatching date = day $0)$. Nestlings were weighed to the nearest $0.1 \mathrm{~g}$ and their tarsus length was measured to the nearest 0.01 $\mathrm{mm}$ with a digital caliper (Svensson 1992). Unmanipulated broods were visited daily from day 16 onwards to establish numbers of fledged and dead young. Hatching success (proportion of eggs hatched), fledging success (proportion of hatchlings that resulted in fledged young), breeding success (proportion of eggs that resulted in fledged young), and offspring size (fledgling mass and tarsus length) were considered as partial measures of reproductive success.

Blood sampling.-We chose 47 females among 123 Pied Flycatcher pairs trapped in 1998 and 57 females among 142 Pied Flycatcher pairs trapped in 1999. A drop of blood from the left brachial vein was collected in a microcapillary tube and transferred to a glass slide, smeared, air-dried, and fixed in absolute ethanol some hours later. Smears were Giemsastained for $45 \mathrm{~min}$ to assess hematozoan infections (Merino and Potti 1995, Merino et al. 1997). Parasite analysis was performed by E. Arriero. Smears were microscopically scanned at $200 \times$ in search of large parasites such as Trypanosoma spp. To prevent the possibility that the symmetry of the blood smear might cause a nonrandom distribution of parasites (Godfray et al. 1987), one-half of each smear was entirely scanned ( $\sim 300$ fields scanned, one-half being chosen at random; Merino and Potti 1995). Subsequently, intraerythrocytic parasites such as Haemoproteus balmorali were detected with oil immersion at $1,000 \times$ in the other half of the smear. Blood-parasite prevalence was defined as proportion of infected females in the sample.

Statistical procedures.-For females that had been sampled in both years, we randomly picked one observation to be included in the analyses to avoid pseudoreplication. Thus, all birds were entered in the analysis only once. Breeding attempts were classified in two categories, deserted (1) and nondeserted (0), during the incubation period. Logistic regression analysis was used to explore variables that may influence the female's decision to desert the clutch, that is, year, blood parasite prevalence. Effect of blood parasites on reproductive performance was analysed 
TABLE 1. Results of logistic regression analysis of factors determining clutch categories (deserted vs. nondeserted) of female Pied Flycatchers during incubation period.

\begin{tabular}{lrrrc}
\hline \hline \multicolumn{1}{c}{ Variable $(n=104)$} & Estimate & $-2 \log$ LR & $\mathrm{df}$ & $P$ \\
\hline Study year & 0.7590 & 5.674 & 1 & 0.0172 \\
Female parasite status by Trypanosoma & 1.2183 & 25.219 & 1 & $<0.001$ \\
Female parasite status by Haemoproteus & 0.2440 & 0.914 & 1 & 0.3389 \\
Interaction (year $\times$ Trypanosoma) & -0.5020 & 2.620 & 1 & 0.1055 \\
Interaction (year $\times$ Haemoproteus) & -0.5143 & 4.139 & 1 & 0.0419 \\
\hline
\end{tabular}

using ANOVA and entering respective breeding parameters as dependent variables. All statistical analyses were performed using SPSS for Windows ${ }^{\circledR}$ (Norusis 1993) and were two-tailed.

Results.- In the present population, 35 and $16 \%$ of females sampled during incubation period were infected with Haemoproteus balmorali and Trypanosoma spp., respectively ( $n=167$; Sanz et al. 2001).

To study effect of blood parasites on decision of females to desert their clutches, a logistic regression analysis was performed of clutch categories (deserted vs. nondeserted) against Haemoproteus balmorali infection status (infected vs uninfected) of females, Trypanosoma spp. infection status of females, and

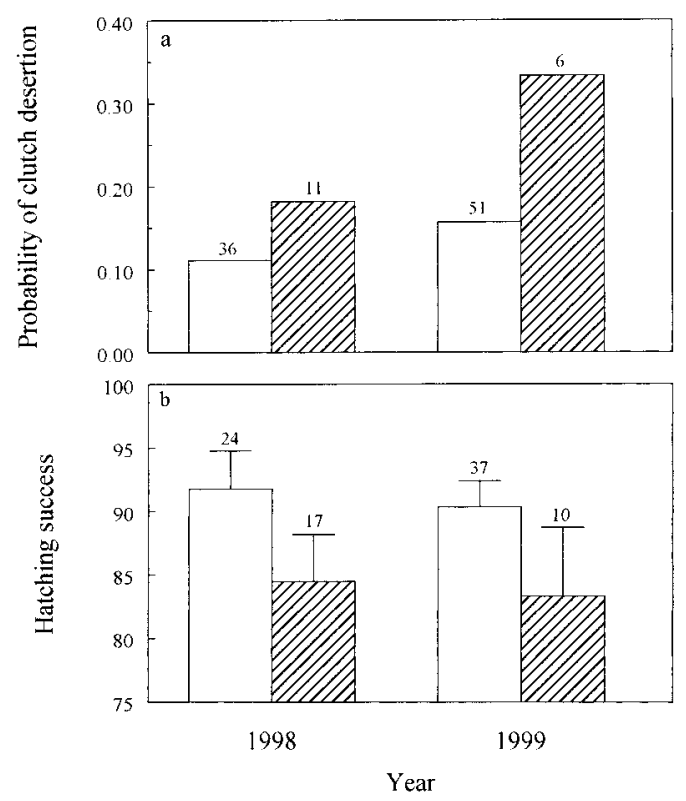

FIG 1. (A) Probability of clutch desertion according to study year and female infection by Trypanosoma spp. (open bars = uninfected females; hatched bars $=$ infected females) during incubation period. (B) Mean hatching success according to study year and female infection by Haemoproteus balmorali (open bars = uninfected females; hatched bars = infected females). The error bars represent the standard error of the mean. Numbers above bars are sample sizes. study year. Probability of clutch desertion was dependent on study year (Table 1), but was independent of female $H$. balmorali infection status (Table 1). A higher number of clutches were deserted during the incubation period in 1999 than in 1998 (Fig. 1a). Probability of clutch desertion was significantly dependent on female Trypanosoma spp. parasite status (Table 1). More clutches were deserted when females were infected by Trypanosoma spp. than when females were uninfected (Fig. 1a). Interaction term between female Trypanosoma spp. parasite status and study year was nonsignificant (Table 1), showing that differences in probability of clutch desertion between study years for infected and uninfected females by Trypanosoma spp. were in the same direction (Fig. 1a).

There were no significant differences in laying date and clutch size between Haemoproteus balmorali infected and uninfected females (Table 2), and between females with or without Trypanosoma spp. infection when the effect of study year was controlled (Table 2). Haemoproteus balmorali infected females had lower hatching success than uninfected females (Table 2; Fig. 1b), and there were no differences in hatching success between females with or without Trypanosoma spp. infection when controlling for the effect of study year (Table 2). There were no differences in incubation period, fledging success, breeding success, fledgling body mass, and tarsus length (mean values per brood) between $H$. balmorali infected and uninfected females (Table 2), and between females with or without Trypanosoma spp. infection when the effect of study year was controlled (Table 2).

Discussion.-We have shown that female Pied Flycatchers infected with Trypanosoma spp. had a higher probability of clutch desertion during incubation period than uninfected females. Moreover, females infected with Haemoproteus balmorali had a lower hatching success than uninfected females. In that southern breeding population, $H$. balmorali was the most common blood parasite for females during incubation period. Species of $H$. balmorali are the most common hemosporidians encountered in free-living birds and are believed to be the least pathogenic of blood parasites (Atkinson and van Riper 1991). However, negative effects may not be easy to document, especially 
TABLE 2. Analyses of variance of reproductive parameters of female Pied Flycatchers in relation to blood parasites prevalences (Haemoproteus balmorali, Trypanosoma spp.) and study years.

\begin{tabular}{|c|c|c|c|c|c|c|c|}
\hline & \multirow[b]{2}{*}{$n$} & \multicolumn{2}{|c|}{ Haemoproteus } & \multicolumn{2}{|c|}{ Trypanosoma spp. } & \multicolumn{2}{|c|}{ Study year } \\
\hline & & $F$ & $P$ & $F$ & $P$ & $F$ & $P$ \\
\hline Laying date & 104 & 2.36 & 0.13 & 0.03 & 0.87 & 11.20 & $<0.001$ \\
\hline Clutch size & 104 & 2.42 & 0.12 & 0.08 & 0.78 & 16.39 & $<0.001$ \\
\hline Incubation period (days) & 88 & 0.45 & 0.50 & 1.11 & 0.29 & 8.84 & 0.004 \\
\hline Hatching success $(\%)$ & 88 & 5.18 & 0.025 & 0.01 & 0.92 & 0.63 & 0.43 \\
\hline Fledging success $(\%)$ & 88 & 3.34 & 0.07 & 1.26 & 0.26 & 2.69 & 0.10 \\
\hline Breeding success (\%) & 88 & 0.00 & 0.94 & 0.43 & 0.51 & 2.05 & 0.16 \\
\hline Fledgling mass $(\mathrm{g})$ & 84 & 1.91 & 0.17 & 0.38 & 0.54 & 1.19 & 0.28 \\
\hline Fledgling tarsus (mm) & 84 & 0.47 & 0.49 & 0.34 & 0.56 & 5.00 & 0.028 \\
\hline
\end{tabular}

in wild birds, without manipulating parasite load (Bennett et al. 1993).

Most studies in free-living breeding birds have focussed on nestling period to study association between blood parasites and host reproductive success (review in Møller et al. 1990, Møller 1997). That may be due to the general perception that incubation period is a time of reduced energy demand compared to other phases of the reproductive period. However, in altricial species, there is no convincing evidence of differences in female energy expenditure during incubation as compared to energy expenditure during the nestling period (Williams 1995, Thomson et al. 1998). In this study, we presented evidence that desertions during the incubation period were higher and hatching success lower for infected females than uninfected females.

Evidence of effects of different genera of blood parasites on breeding performance during incubation period has been reported in two passerine species. Dufva (1996) has shown that female Great Tits (Parus major) carrying Trypanosoma hatched proportionally fewer eggs compared to females without Trypanosoma. However, female Great Tits were sampled when nestlings reached an age of 13 days, and a relatively small number of birds were infected by that blood parasite (three females in four years; Dufva 1996). Sample size is too small to support the conclusion that lower hatching success was a consequence of parasitism (Dufva 1996). In another study, Widemo (1989) has reported that Collared Flycatchers (Ficedula albicollis) suffering from malaria take longer to incubate their eggs (see reference in Møller et al. 1990). On the other hand, physiological studies of hemotozoan infections have shown that acute infections may have significant effects on oxygen transport and ability to thermoregulate in birds (Hayworth et al. 1987). Hayworth et al. (1987) found that captive canaries infected by Plasmodium relictum have decreased ability to thermoregulate and lowered oxygen capacity at the crisis stage when peripheral parasitemia reaches a peak. That study suggested that hemotozoan infections may be especially important if the peak of parasitemia coincides with thermally stressing conditions (Hayworth et al. 1987). Females infected by blood parasites during incubation period may have decreased ability to thermoregulate which might affect their incubation capacity. Moreover, there may be a trade-off during the incubation period between resources that females invest in reproductive activities and those invested in mounting an immune response to blood parasites (Gustafsson et al. 1994, Sheldon and Verhulst 1996, Lochmiller and Deerenberg 2000, Norris and Evans 2000).

Our observational study shows that females infected with Haemoproteus balmorali experience a lower hatching success, and that those females or their mates may compensate for that negative effect during the nestling period. Haemoproteus balmorali infected females tended to have higher fledging success than noninfected ones, but that difference was not statistically significant. That may explain why there were no differences in breeding success, fledgling mass, and tarsus length between $H$. balmorali infected and uninfected females. Thus, $H$. balmorali infected female Pied Flycatchers might not suffer from reduced individual fitness after egg laying. We suggest that blood parasitemia might have important consequences on maternal reproductive performance during incubation period, a thermally stressful period. Females' blood-parasite loads were measured at the beginning of the incubation period and an association with their reproductive success was shown. We found negative effects of blood parasites only during the incubation period: higher probability of clutch desertion or lower hatching success.

Acknowledgments.-We thank C. Acosta, I. Nogueras, J. C. Orellana, and J. M. Llama for help in the field, and two anonymous reviewers for constructive comments on the manuscript. This is a contribution from the field station "El Ventorrillo," Museo Nacional de Ciencias Naturales (CSIC). The study was financed by project PB97-1233-C02-01 of the DGESIC (Spanish Ministry of Education and Culture). The Dirección General para la Conservación de la Naturaleza donated the nestboxes, whereas Javier Donés (Montes de Valsain, Organismo Autónomo Parques Nacion- 
ales) gave permission to work in the study area. Finally, the Dirección General del Medio Natural of the Junta de Castilla y León gave licence (EP-71/98 and EP-12/99) for capturing, banding and handling birds.

\section{Literature Cited}

Allander, K. 1997. Reproductive investment and parasite susceptibility in the Great Tit. Functional Ecology 11:358-364.

Allander, K., AND G. F. BenNetT. 1995. Retardation of breeding onset of Great Tits (Parus major) by blood parasites. Functional Ecology 9:677-682.

Appleby, B. M., M. A. AnWAR, And S. J. Petty. 1999. Short-term and long-term effects of food supply on parasite burdens in Tawny Owls, Strix aluco. Functional Ecology 13:315-321.

AtKinson, C. T., AND C. VAN RIPER III. 1991. Pathogenicity and epizootiology of avian haematozoa: Plasmodium, Leucozytozoon and Haemoproteus. Pages 19-48 in Bird-Parasite Interactions: Ecology, Evolution and Behaviour (J. E. Loye and M. Zuk, Eds.). Oxford University Press, Oxford.

Bennett, G. F., M. A. Peirce, And R. W. Ashford. 1993. Avian haematozoa: Mortality and pathogenicity. Journal of Natural History 27:993-1001.

DufVA, R. 1996. Blood parasites, health, reproductive success, and egg volume in female Great Tits Parus major. Journal of Avian Biology 27:8387.

FARGallo, J. A., AND S. Merino. 1999. Brood size manipulation modifies the intensity of infection by haematozoa in female Blue Tits Parus caeruleus. Ardea 87:261-268.

Forbes, M. R. L. 1993. Parasitism and host reproductive effort. Oikos 67:444-450.

Godfray, R. D., A. M. Fedynich, And D. B. Pence. 1987. Quantification of hematozoa in blood smears. Journal of Wildlife Disease 23:558-565.

Gustafsson, L., D. Nordling, M. S. Andersson, B. C. SHELDON, AND A. QVARnSTROM. 1994. Infectious diseases, reproductive effort and the cost of reproduction in birds. Philosophical Transactions of the Royal Society of London, Series B 346:323-331.

Hayworth, A. M., C. VAN Riper III, AND W. W. WeAtHeRs. 1987. Effects of Plasmodium relictum on the metabolic rate and body temperature in canaries (Serinus canarius). Journal of Parasitology 73:850-853.

Ilmonen, P., H. Hakkarainen, V. Koivunen, E. KorpimäKI, A. Mullie, AND D. SHUtler. 1999. Parental effort and blood parasitism in Tengmalm's Owl: Effects of natural and experimental variation in food abundance. Oikos 86:79-86.

KorpimÄKI, E., H. HAKKARAINEN, AND G. F. BENNETT. 1993. Blood parasites and reproductive success of Tengmalm's Owls: Deterimental ef- fects on females but not on males? Functional Ecology 7:420-436.

Lochmiller, R. L., AND C. DeERENBERG. 2000. Tradeoffs in evolutionary immunology: Just what is the cost of immunity? Oikos 88:87-98.

LOYE, J. E., AND M. ZUK, EDS. 1991. Bird-Parasite Interactions: Ecology, Evolution and Behaviour. Oxford University Press, Oxford.

Lundberg, A., And R. V. Alatalo. 1992. The Pied Flycatcher. Poyser, London.

Merino, S., AND J. POTTI. 1995. High prevalence of hematozoa in nestlings of a passerine species, the Pied Flycatcher (Ficedula hypoleuca). Auk 112: 1041-1043.

Merino, S., J. Potti, And F. A. Fargallo. 1997. Blood parastites of passerine birds from central Spain. Journal of Wildlife Disease 33:638-641.

Merino, S., J. PotTi, AND J. Moreno. 1996. Maternal effort mediates the prevalence of trypanosomes in the offspring of a passerine bird. Proceedings of the National Academy of Science USA 93: 5726-5730.

Møller, A. P. 1997. Parasites and the evolution of host life history. Pages 105-127 in Host-Parasite Evolution: General Principles and Avian Models (D. Clayton and J. Moore, Eds.). Oxford University Press, Oxford.

Møller, A. P., K. Allander, And R. Dufva. 1990. Fitness effects of parasites on passerine birds: A review. Pages 269-280 in Population Biology of Passerine Birds: An Intergrated Approach (J. Blondel, A. Gosler, J.-D. Lebreton, and R. H. McCleery, Eds.). Springer-Velag, Berlin.

Norris, K., M. ANWAR, AND A. F. ReAD. 1994. Reproductive effort influences the prevalence of haematozoan parasites in Great Tits. Journal of Animal Ecology 63:601-610.

NorRIS, K., AND M. R. EvAns. 2000. Ecological immunology: Life history trade-offs and immune defense in birds. Behavioral Ecology 11:19-26.

NorUsis, M. J. 1993. SPSS Advanced Statistics User's Guide. SPSS, Chicago.

Oppliger, A., P. Christe, AND H. Richner. 1997. Clutch size and malarial parasites in female Great Tits. Behavioral Ecology 8:148-152.

Ots, I., AND P. HõRAK. 1996. Great Tits Parus major trade health for reproduction. Proceedings of the Royal Society of London, Series B 263:14431447.

Richner, H., P. Christe, And A. Oppliger. 1995. Parental investment affects prevalence of malaria. Proceedings of the National Academy of Science USA 92:1192-1194.

SANZ, J. J. 1997. Geographic variation in breeding parameters of the Pied Flycatcher Ficedula hypoleuca. Ibis 139:107-114.

Sanz, J. J., E. Arriero, J. Moreno, and S. Merino. 2001. Interactions between hemoparasite status 
and female age in the primary reproductive output of Pied Flycatchers. Oecologia 126:339-344.

SHeldon, B. C., AND S. Verhulst. 1996. Ecological immunology: Costly parasite defenses and trade-offs in evolutionary ecology. Trends in Ecology and Evolution 11:317-321.

SiIKAMÄKI, P., O. RÄtTI, M. Hovi, AND G. F. BennetT. 1997. Association between haematozoan infections and reproduction in the Pied Flycatcher. Functional Ecology 11:176-183.

Stearns, S. C. 1992. The Evolution of Life Histories. Oxford University Press, Oxford.

SvenSSON, L. 1992. Identification Guide to European Passerines. Fingraf AB, Stockholm, Sweden.

Thomson, D. L., P. Monaghan, And R. W. Furness. 1998. The demands of incubation and avian clutch size. Biological Review 73:293-304.

WidemO, F. 1989. Effect of blood parasites on the Collared Flycatcher Ficedula albicollis. Honors thesis,
Department of Zoology, Uppsala University, Uppsala, Sweden.

WIEHN, J., AND E. KORPIMÄKI. 1998. Resource levels, reproduction and resistance to haematozoan infections. Proceedings of the Royal Society of London, Series B 265:1197-1201.

Wiehn, J., E. KorpimÄKI, AND I. PeN. 1999. Haematozoan infections in the Eurasian Kestrel: Effects of fluctuating food supply and experimental manipulation of parental effort. Oikos 84:87-98.

WiLliams, J. B. 1997. Energetics of avian incubation. Pages 375-415 in Avian Energetics and Nutritional Ecology (C. Carey, Ed.). Chapman and Hall, New York.

Received 5 August 2000, accepted 25 January 2001.

Associate Editor: C. Blem 